\title{
The addition of monosodium glutamate and inosine monophosphate-5 to high-protein meals: effects on satiety, and energy and macronutrient intakes
}

\author{
Natalie D. Luscombe-Marsh ${ }^{1,2}$, Astrid J. P. G. Smeets ${ }^{1,2}$ and Margriet S. Westerterp-Plantenga ${ }^{1,2}$ \\ ${ }^{1}$ Department of Human Biology, Maastricht University, PO Box 616, 6200 MD, Maastricht, The Netherlands \\ ${ }^{2}$ Top Institute Food \& Nutrition (TIFN), PO Box 557, 6700 AN, Wageningen, The Netherlands
}

(Received 12 May 2008 - Revised 17 December 2008 - Accepted 26 January 2009 - First published online 9 March 2009)

In a fed and orally stimulated state, whether the addition of monosodium glutamate (MSG) (alone or in combination with inosine monophosphate-5 (IMP-5)) to a high-protein (HP) meal leads to early satiety and a difference in energy intake at a second course was investigated. Ten men and twelve women consumed, in random order, a first-course meal consisting of: (1) water (control); (2) a HP meal with 0.6\% MSG and 0.25\% IMP-5; (3) a HP meal with no additives; (4) a HP meal with MSG only; (5) a sham-fed meal 2 (oral-stimulation). Appetite perceptions, plasma concentrations of glucagon-like peptide 1 (GLP-1), glucose and insulin, and energy intake at a buffet (i.e. a second course) were measured before and after each condition. Changes in appetite, and in GLP-1, glucose and insulin, were similar for the three fed HP conditions and all were greater ( post hoc all $P<0.01$ ) than the control and sham conditions. Energy intake was not different following the HP + MSG + IMP (1.86 (SEM 0.3) $\mathrm{MJ})$ as compared with the HP + MSG-only (2.24 (SEM 0.28) MJ) condition $(P=0 \cdot 08)$, or for the HP + MSG + IMP compared with the HP no-additives condition (1.60 (SEM 0.29) MJ) ( $P=0 \cdot 21)$. Following the HP + MSG-only condition, 0.64 (SEM 0.20) MJ more energy was consumed compared with the HP no-additives condition $(P=0.005)$. We conclude that the addition of MSG to a HP meal does not influence perceptions of satiety and it may increase energy intake at a second course. Cephalic responses after the sham condition were of similar magnitude to the control and therefore just tasting food is not enough to influence appetite and energy intake.

Monosodium glutamate: Appetite: Energy intake: Satiety

Nutritionists treating individuals for weight loss continually look for new food ingredients that can further enhance the effectiveness of successful dietary treatments. Protein-rich foods have become popular for the dieting public because protein is more satiating and more thermogenic than isoenergetic loads of carbohydrate and fat ${ }^{(1-7)}$. Protein-rich foods contain free glutamate and inosine monophosphate-5 (IMP-5) and these ingredients are associated with a unique taste often described as 'Umami' (or 'savoury/meaty' to Westerners) ${ }^{(8,9)}$. Anecdotal evidence suggests that the unique 'Umami' taste of glutamate and IMP-5 functions as a signal to regulate protein intake. A small body of scientific evidence is emerging to support this notion. Recently in thirty-six women and twenty-four men, we observed that the taste detection threshold of glutamate given orally as monosodium glutamate (MSG), and in combination with IMP-5, appears to predict one's 'liking' and 'preference' of high-protein (HP) foods ${ }^{(10)}$. Other studies in rats, non-primates and human subjects have also demonstrated that a preference for dietary protein (or liking of) is related, in part, to the way the body senses and tastes MSG and on the body's protein requirements and stores at the time ${ }^{(11-17)}$. In the present study, we found that individuals who were the most sensitive to the taste of MSG (i.e. those who could correctly detect low concentrations (i.e. $0 \cdot 1$ to $0 \cdot 4 \%$ ) ) also reported a greater liking and preference of protein-rich foods ${ }^{(10)}$. Interestingly, Murphy showed that individuals who preferred higher concentrations of MSG in solution had a lower nutritional/protein status than those who preferred lower concentrations of $\mathrm{MSG}^{(18)}$. This leads us to speculate that the taste detection threshold for MSG may relate to a preference for protein when given a choice of different foods, and ultimately, it may relate to habitual protein intake. That is, individuals with a low, rather than a high detection threshold, may more readily consume an adequate protein intake and consequently achieve a balanced nutritional status intake.

In addition to MSG and IMP-5 indicating a 'liking' or 'preference' for protein, Bellisle et al. showed that the addition of $0.6 \%$ MSG to novel nutritionally valuable foods of medium palatability increased the spontaneous intake of them without affecting overall energy intake (due to a reduction in intake of non-MSG-enriched foods), in both a healthy elderly and diabetic elderly population ${ }^{(19-21)}$. In thirty-two healthy individuals, Rodgers \& Blundell ${ }^{(22)}$ found that the addition of $20 \%$ (dry weight) MSG to soup made it significantly more 'pleasant', 'savoury' and 'satisfying' than a soup without MSG and, once again, there was no difference in subsequent energy intake despite there being a more rapid recovery of

Abbreviations: GLP-1, glucagon-like peptide 1; HP, high-protein; IMP, inosine monophosphate; MSG, monosodium glutamate.

* Corresponding author: Dr Natalie Luscombe-Marsh, fax + 3143367 0976, email natalie.luscombe-marsh@hotmail.com 
hunger over $60 \mathrm{~min}$ after the $20 \%$ MSG soup. Furthermore, Essed et al. ${ }^{(23)}$ performed a single-blind randomised 16 weeks parallel study in elderly nursing home patients where they added $700 \mathrm{mg}$ flavour and/or $300 \mathrm{mg}$ MSG to the animal protein part of the cooked lunchtime meal. After 16 weeks, they found that enhancing the taste of the protein component of the meal did not lead to a higher overall energy intake at lunch, nor did it increase body weight. In this study, however, it was unclear whether there was a period of adjustment within the first day(s) of changing the diet in the acute effects of MSG on energy and protein intakes. This is of interest because in the flavour + MSG group, they observed a mean $1 \mathrm{~kg}$ reduction in body weight $(0 \mathrm{~kg}$ change in the control group) which potentially could be related to the increase in total weight of protein consumed (i.e. protein may have promoted a greater thermogenesis and satiety, and therefore reduced day-long energy intake in the first few weeks of the 16-week period). In addition, the nursing home population was heterogeneous and this, too, may have masked small differences between the treatment and control group.

Oro-sensory stimulation by different food properties evokes cephalic responses that are involved in the regulation of food intake and body weight but our understanding of them remains unclear. Cephalic responses consist of vagal cholinergic activity initiated by the thought, sight, smell and taste of food. Experimentally they are evoked using modified sham feeding (i.e. tasting but not ingesting a meal). Sham feeding followed by enteric and gastric fat loads have been shown to bring about earlier responses in perceptions of satiety and in the postprandial profiles of TAG, lipoprotein and insulin concentrations $^{(24-26)}$. Heath et al. also found that sham feeding before administering a $50 \mathrm{~g}$ fat load suppressed the ghrelin response ${ }^{(24)}$. To our knowledge, no human studies have examined the effect of added MSG on cephalic responses evoked by the vagus nerve and whether they influence postprandial satiety and subsequent food intake.

The aim of the present study was to determine, in a fed and orally stimulated state (sham feeding), whether the addition of MSG to a HP meal leads to an early satiety and difference in energy and macronutrient compositions eaten at a subsequent buffet meal. In healthy subjects, we speculate that both cephalic and postprandial responses will contribute to the observed effects. None of the aforementioned studies have examined the effects of MSG on satiety hormones. In healthy women fed, at energy balance, a high- or adequate-protein diet for $4 \mathrm{~d}$, our group previously showed that $24 \mathrm{~h}$ satiety is related to an increased release of GLP- $1^{(1)}$. The effect of MSG-induced GLP-1 release and its relationship to subjective satiety will therefore be investigated. If the addition of MSG is found to affect satiety, energy intake or protein intake at the buffet, then the relationship between the taste detection threshold and these outcomes will be determined.

\section{Subjects and methods}

\section{Subjects}

Subjects were recruited from advertisements in a local newspaper and around the Maastricht University. Inclusion criteria were healthy men and women aged 18-65 years, non-smokers, on no medication (except the contraceptive pill), not known to be allergic to MSG or other foods, not dietary restrained (assessed using the Three Factor Eating Questionnaire ${ }^{(27)}$ ), low to moderate alcohol use (i.e. two or fewer standard drinks per $\mathrm{d}$ for no more than $5 \mathrm{~d} /$ week), a BMI between 20 and $30 \mathrm{~kg} / \mathrm{m}^{2}$ and weight stable $(<3 \%$ change over the 3 months before screening). Fat and fat-free mass was determined for each subject from the measurement of total body water using ${ }^{2} \mathrm{H}$ dilution and the assumption that total body water occupies an approximate average of $73.2 \%$ of the fat-free mass ${ }^{(28,29)}$.

Twelve women and ten men were enrolled in the study that was approved by the Medical Ethics Committee of Maastricht University. All subjects gave written informed consent to participate.

\section{Study design}

As part of a separate study that has been published ${ }^{(10)}$, all subjects underwent a series of 'triangle taste tests' to determine their sensitivity to the taste of MSG. In brief, the 'triangle taste test' methodology that we used involved the presentation of ten rows of triplicate cups with $8 \mathrm{ml}$ soup (total of thirty cups). Within each triplicate, either one or two cups contained soup with added MSG. The remaining cups contained soup with no added MSG. Subjects were instructed to taste (but not swallow) half the volume of each soup cup and they were allowed to re-taste each sample if necessary. They were asked to 'identify' the soup with the 'added MSG' and 'how certain they were about their choice'. The starting concentration was $0.4 \%(\mathrm{w} / \mathrm{w}) \mathrm{MSG}$. If they could correctly detect the soup with added $0.4 \%$ MSG for eight or more of the triplicates then the concentration was decreased (or if not, it was increased) by a step of $0.1 \%$ until the detection threshold for the taste of MSG was determined (within the concentration range of $0 \cdot 1-0.8 \%$ ). Between each cup within the 'triangle taste test', subjects were encouraged to rinse their mouth with water and chew on plain white bread (but not swallow) to get rid of previous tastes. Moreover, a 1015 min break was taken between each 'triangle taste test' so that subjects could again rinse their mouth with water or chew on plain white bread to get rid of previous tastes.

Following determination of the detection threshold for the taste of MSG, twenty-two subjects underwent a singleblinded, randomised cross-over design. On five experimental sessions 1 week apart, subjects consumed in random order the following meal conditions: (1) control (water); (2) a HP meal with $0.6 \%$ MSG and $0.25 \%$ IMP-5 added $(\mathrm{HP}+$ MSG + IMP); (3) a HP meal with no additives (HP no-additives); (4) a HP meal with MSG only added (HP + MSG); (5) sham-fed meal 2 (sham HP + MSG + IMP). The reason that condition 2 was included was because we had previously demonstrated that the addition of $0.25 \%$ IMP-5 lowered the concentration of MSG detected in a soup solution from $0.33 \%$ to $0.26 \%{ }^{(10)}$. In the sham-fed condition, food was chewed and expectorated at the time when swallowing would normally occur to represent oral stimulation only. For all other conditions the water or food was completely ingested. Figure 1 depicts the study schedule for each experimental session; each session ran for approximately $1.5 \mathrm{~h}$. Subjects were asked to come to the clinic at 08.30 hours after having 
Cannula
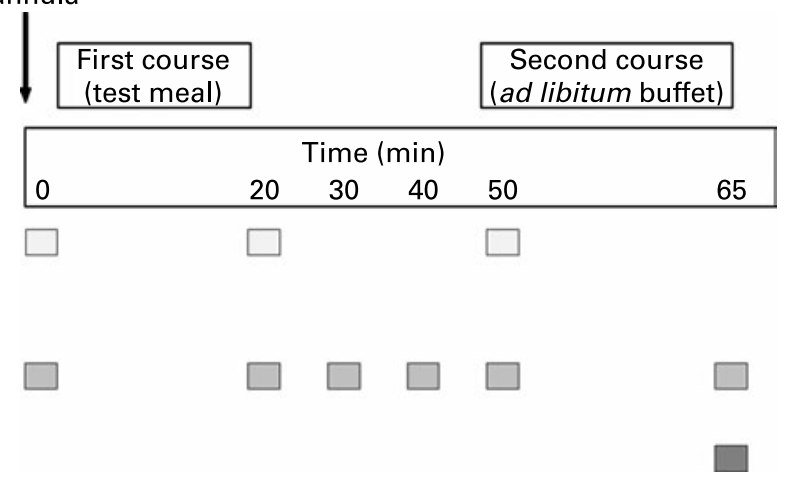

Fig. 1. Schema of the protocol that subjects underwent at the five experimental sessions, each separated by at least 1 week. In random order, subjects consumed, over $20 \mathrm{~min}$, one of the five meal conditions: (1) control (water); (2) a high-protein (HP) meal with monosodium glutamate (MSG) and inosine monophosphate-5 (IMP-5); (3) a HP meal with no added MSG; (4) a HP meal with MSG only; (5) a sham-fed HP meal with MSG and IMP-5. Conditions 2 to 5 consisted of a bowl of vegetable soup and a wholemeal bread roll containing minced beef and salad and were isoenergetic. The control consisted of an equal weight of water. Subjects were given $20 \mathrm{~min}$ to completely ingest each of the conditions 1 to 4 . For the sham-fed condition, subjects chewed the food and expectorated it at the time when swallowing would normally occur to represent oral stimulation. At $\mathbf{3 0}$ min later they were allowed to eat whatever they wanted until they were 'comfortably full/satisfied' from a buffet containing six protein-rich and six carbohydrate-rich foods (i.e. the second course). At $t=0$, 20 and $50 \mathrm{~min}$, blood was taken for determination of glucose, insulin and glucagon-like peptide $1(\square)$. At $t=0,20,30,40,50$ and $65 \mathrm{~min}, 100 \mathrm{~mm}$ visual analogue scales were completed $(\square)$. At $65 \mathrm{~min}$, energy and macronutrient intakes eaten at the buffet meal were assessed $(\square)$.

fasted for $12 \mathrm{~h}$ (water to prevent thirst, if necessary, was allowed overnight). Subjects were instructed to eat (or sham eat) the respective conditions over $20 \mathrm{~min}$ (these conditions represented a first course). Before and at several times after each first-course meal, $100 \mathrm{~mm}$ visual analogue scales were completed to assess pleasantness of taste of the meal and appetite. In addition, blood was taken via an intravenous catheter on the back of the hand to measure plasma markers of satiety (glucose, insulin and GLP-1). After 30 min later, a buffet containing six protein-rich and six carbohydrate-rich food items were offered to subjects and they could eat whatever they wanted over $15 \mathrm{~min}$ or until 'comfortably full' (the buffet represented a second course). Energy and macronutrient intakes eaten at the second course were determined. Appetite ratings before and after the second-course buffet were also collected.

\section{First-course meal conditions}

The control meal was water and contained no energy. Meal conditions 2-5 were isoenergetic and the energy content for each subject was calculated using the Harris-Benedict equation to provide $20 \%$ of the daily energy requirements $(2.2 \text { (SEM 0.7) MJ })^{(30)}$; the macronutrient composition was $30 \%$ energy from protein, $30 \%$ from fat and $40 \%$ from carbohydrate. All meals were of equal weight. Conditions 2 to 5 consisted of vegetable soup and one to two rolls filled with minced meat and salad (the number of rolls provided the remainder of the $20 \%$ of daily energy). The soup consisted of $400 \mathrm{ml}$ soup stock (i.e. $250 \mathrm{~g}$ Vectra ${ }^{\circledR}$ vegetable boullion (Natudis B.V., Harderwijk, The Netherlands) dissolved in 1 litre of water) to which $3 \mathrm{~g}$ Protifar ${ }^{\circledR}$ protein powder (Nutricia Clinical Care, Trowbridge, Wilts, UK), $10 \mathrm{~g}$ egg noodles and $20 \mathrm{~g}$ finely grated soup vegetable were added. The rolls each consisted of a $42 \mathrm{~g}$ wholemeal bread roll, $100 \mathrm{~g}$ prepared minced beef filling (recipe below), $5 \mathrm{~g}$ diet margarine, $20 \mathrm{~g}$ tomato, $10 \mathrm{~g}$ cucumber, $10 \mathrm{~g}$ lettuce and $7 \mathrm{~g}$ Protifar $^{\circledR}$ protein powder (Nutricia Clinical Care). The minced beef filling was prepared in daily batches (i.e. $175 \mathrm{~g}$ fine minced beef, $20 \mathrm{~g}$ onion, $10 \mathrm{~g}$ olive oil and $650 \mathrm{~g}$ organic tomato paste). All food items used in the recipes, except when specified otherwise, were purchased from the local Albert Hein $^{\text {тM }}$ supermarket. MSG and IMP-5 were purchased as salts from Ajinomoto Foods Germany GmbH (Hamburg, Germany) and the salts were dissolved into the soup and minced beef filling. Concentrations of $0.6 \%$ (w/w) MSG (i.e. the weight of MSG per weight of soup and roll) and $0.25 \%(w / w)$ IMP-5 were selected because they are concentrations typically added to commercial food and are similar to levels of naturally occurring glutamate found in traditional dishes ${ }^{(31,32)}$. No salt (sodium chloride) was added to the meals. The soup was served warm $\left(55^{\circ} \mathrm{C}\right)$. Subjects were given $20 \mathrm{~min}$ to completely ingest each of the meals. For the sham-fed condition, subjects were asked to use $200 \mathrm{ml}$ water provided to rinse their mouths and expectorate the chewedup food into a bowl; they were asked not to drink the water. The weight of the meal expectorated was measured at the end of the session to determine how much may have been ingested.

\section{Second-course buffet}

The buffet consisted of six protein-rich and six carbohydraterich snack food items that were purchased from the local Albert Hein ${ }^{\mathrm{TM}}$ supermarket. All twelve foods were presented simultaneously $30 \mathrm{~min}$ after subjects completed their firstcourse meal. Subjects were not informed that overall energy or macronutrient intakes consumed at the buffet were being investigated. The protein-rich food items were Albert Hein ${ }^{\text {TM }}$ fruit kwark, Albert Hein ${ }^{\mathrm{TM}}$ natural European yoghurt, Albert Hein $^{\mathrm{TM}}$ unsalted peanuts, Frico ${ }^{\circledR}$ slices of hard cheese and Albert Hein ${ }^{\mathrm{TM}}$ shoulder ham and portions of Slim Fast ${ }^{\circledR}$ protein-rich muesli bar. The carbohydrate-rich food items were Albert Hein ${ }^{\mathrm{TM}}$ custard dessert with cream, Albert Hein ${ }^{\mathrm{TM}}$ vanilla rice dessert, Euro Shopper ${ }^{\mathrm{TM}}$ plain water crackers, Shuttles ${ }^{\circledR}$ cheese-flavoured crackers, Lays ${ }^{\circledR}$ potato crisps and $\mathrm{C} 1000^{\mathrm{TM}}$ chocolate-chip cookies. All foods were presented in excess quantities in transparent plastic bowls and white plates of equal size. The protein content of the protein-rich food items that were offered at the buffet ranged from 7 to $37 \mathrm{~g}$ protein $/ 100 \mathrm{~g}$ food whereas the carbohydrate-rich items contained between 3 and $11 \mathrm{~g}$ protein $/ 100 \mathrm{~g}$. Overall, the percentage of energy from protein presented for the protein-rich buffet was $45 \%$ whereas it was $9 \%$ for the carbohydraterich buffet items $(P<0 \cdot 001)$. Energy derived from fat for the protein-rich and carbohydrate-rich categories was not different (31 v. 35\%; $P=0 \cdot 7)$. Subjects could eat whatever items they wanted from the buffet until they were 'comfortably full' and 'comfortably satiated'. Food was removed after $15 \mathrm{~min}$. No water was allowed over the buffet period. 


\section{Appetite ratings}

Satiety, hunger, fullness, desire to eat and prospective future consumption were assessed using validated $100 \mathrm{~mm}$ visual analogue scales ${ }^{(33)}$ completed immediately before and after the first-course meal, as well as at 10, 20 and $30 \mathrm{~min}$ after it (i.e. $t=0,20,30,40$ and $50 \mathrm{~min}$; Fig. 1). The questions (for example, 'How pleasant is the soup?', 'How hungry are you?') were anchored at opposing ends of the $100 \mathrm{~mm}$ horizontal line by 'not at all' and 'very' and subjects were asked to mark the line to indicate how they felt at that moment.

\section{Blood sampling}

Blood was drawn immediately before and after, as well as at $50 \mathrm{~min}$ after, the start of the first course (i.e. $t=0,20,30$, 40 and $50 \mathrm{~min}$; Fig. 1) for the measurement of plasma glucose, insulin and glucagon-like peptide 1 (GLP-1) concentrations. Blood samples were collected in tubes containing EDTA to prevent clotting. Samples for GLP-1 $(4 \mathrm{ml})$ were mixed with $40 \mu \mathrm{l}$ of dipeptidyl peptidase IV (DPP-IV) inhibitor (Linco Research Inc., St Charles, MO, USA) to prevent degradation. Plasma was obtained by centrifugation $\left(4^{\circ} \mathrm{C} ; 3000 \mathrm{rpm}\right.$; $10 \mathrm{~min}$ ), immediately frozen in liquid $\mathrm{N}_{2}$ and stored at $-80^{\circ} \mathrm{C}$ until analysed. Glucose concentrations were determined using the hexokinase method (Glucose HK 125 kit; ABX Diagnostics, Montpellier, France). Plasma concentrations of insulin were measured by RIA (Linco Research Inc.). Plasma active GLP-1 samples were analysed using enzyme-linked immunoradiometric assay (EGLP-35K; Linco Research Inc.).

\section{Determination of energy and macronutrient intakes at the second-course buffet}

Food presented in the buffet was weighed before presentation and after the experimental session. The buffet was presented immediately after the $50 \mathrm{~min}$ appetite questionnaire was marked. Energy and macronutrient intakes eaten at the buffet were assessed by difference. Following the sham and three HP fed conditions, the degree of adjustment in total energy consumed at the second course was calculated using the following formula which had the control condition (i.e. no energy consumed at the first course) as the reference condition: ((total energy intake at first + second course) - energy intake at second course in control condition)/energy intake at second course in control condition $\times 100 \%$.

\section{Statistical analysis}

All data are presented as mean values with their standard errors unless stated otherwise. Statistical analyses were made using SPSS for Windows (version 11.5; SPSS Inc., Chicago, IL, USA), and the criterion for significance (two-tailed) was set at $P<0 \cdot 05$. Repeated-measures ANOVA with meal condition as the between-subject factor was used to determine differences between the conditions for pleasantness of taste and appetite ratings, energy and macronutrient intakes, and plasma concentrations of glucose, insulin and GLP-1. If an overall effect of condition was found, post hoc analyses were done using the least significant difference method of adjustment for multiple comparisons (equivalent to no adjustments). Pearson correlation analysis was done to determine if there was a relationship between the taste detection threshold for MSG $+0.25 \%$ IMP-5 and energy intake at the second course.

\section{Study power}

The study had a $100 \%$ power $(\alpha=0.05)$ with twenty-two subjects to detect an overall effect of condition on energy intake at the buffet. To detect, between the three fed HP conditions, a mean difference in energy intake at the second course of 650 (SD 961) kJ, the study had $80 \%$ power $(\alpha=0.05)$ when using the least significant difference method for multiple comparisons.

\section{Results}

The characteristics of the subjects who completed the study are shown in Table 1. After the first bite of each first-course meal, 'pleasantness of taste' ratings were not significantly different (57.9 (SEM 3.6) mm (control) v. 60.9 (SEM 3.1) $\mathrm{mm}$ $(\mathrm{HP}+\mathrm{MSG}+\mathrm{IMP}-5)$ v. $52.4($ SEM 3.5$) \mathrm{mm}(\mathrm{HP}+$ no additives) v. 59.3 (SEM 3.2) $\mathrm{mm}$ (HP + MSG only) v. 64.9 (SEM 3.7) $\mathrm{mm}$ (sham HP + MSG + IMP-5); overall effect of condition, $P=0.07)$. For the sham-fed condition the weight of the meal expectorated by subjects was on average 88 (SEM 2.2) $\%$.

Table 1. Characteristics of the men and women who completed the study

(Mean values and standard deviations)

\begin{tabular}{|c|c|c|c|c|c|}
\hline & \multicolumn{2}{|c|}{ Men $(n 10)$} & \multicolumn{2}{|c|}{ Women (n 12) } & \multirow[b]{2}{*}{ Sex effect $(P)$} \\
\hline & Mean & SD & Mean & SD & \\
\hline Age (years) & 44 & 19 & 32 & 19 & 0.06 \\
\hline $\mathrm{BMI}\left(\mathrm{kg} / \mathrm{m}^{2}\right)$ & 26.5 & 3.8 & 23.7 & 4.5 & 0.05 \\
\hline Total body water $(\mathrm{kg})$ & $46 \cdot 1$ & 7.5 & 33.8 & $6 \cdot 6$ & $<0.001$ \\
\hline Body fat mass $(\mathrm{kg})$ & $21 \cdot 4$ & 8.9 & $21 \cdot 0$ & $12 \cdot 7$ & 0.90 \\
\hline Body fat-free mass $(\mathrm{kg})$ & 63.2 & $10 \cdot 8$ & $46 \cdot 3$ & 8.9 & $<0.001$ \\
\hline Dietary restraint & $6 \cdot 7$ & $4 \cdot 2$ & $8 \cdot 0$ & $5 \cdot 2$ & 0.40 \\
\hline Lowest concentration of MSG + IMP- 5 tasted ${ }^{*}$ & 0.34 & 0.22 & 0.29 & 0.24 & 0.64 \\
\hline
\end{tabular}

MSG, monosodium glutamate; IMP-5, inosine monophosphate-5.

* Lowest concentration of MSG within the range of $0 \cdot 1-0 \cdot 8 \%$ that could be correctly identified. 


\section{Changes in appetite ratings}

Baseline values for hunger, fullness, satiety, desire to eat and prospective consumption were not significantly different between the meal conditions (all $P>0 \cdot 1$ ). Appetite profiles for each of the five meal conditions are shown in Fig. 2. There was an overall effect of first-course meal condition for all appetite profiles (overall effect, $P<0.001$ ). Compared with the control, the HP meal with added MSG + IMP-5, the HP meal with no added MSG and the HP meal with only MSG all increased satiety and fullness, and decreased hunger, desire to eat and prospective consumption (all post hoc comparisons, $P<0.05)$. There were no significant differences between the three HP fed conditions. For the sham-fed as compared with the control condition, there was no difference for each appetite profile. Sham feeding increased satiety and fullness, and reduced hunger, desire to eat and prospective consumption, but the changes were less than observed in each of the three HP fed conditions (all post hoc comparisons, $P<0 \cdot 01$ ).

For fullness and satiety, there were significant time $X$ condition interactions at $t=20 \mathrm{~min}(P<0.01)$. For fullness, the sham condition produced the lowest post-meal ratings compared with all other conditions (all $P<0 \cdot 04$ ). For satiety, the sham condition produced the lowest post-meal ratings compared with all conditions (post hoc $P<0.001$ ), except the control (post hoc $P=0 \cdot 21$ ). (a)

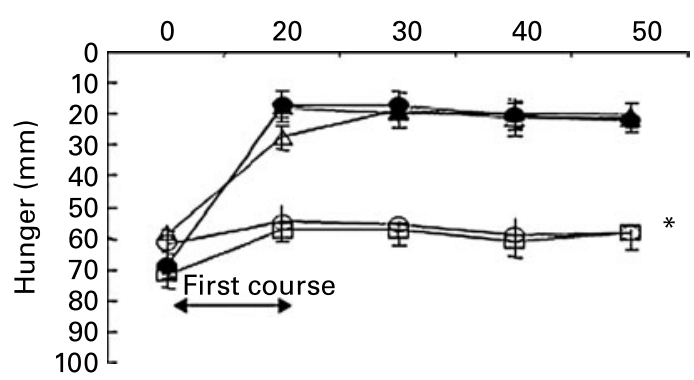

(c)

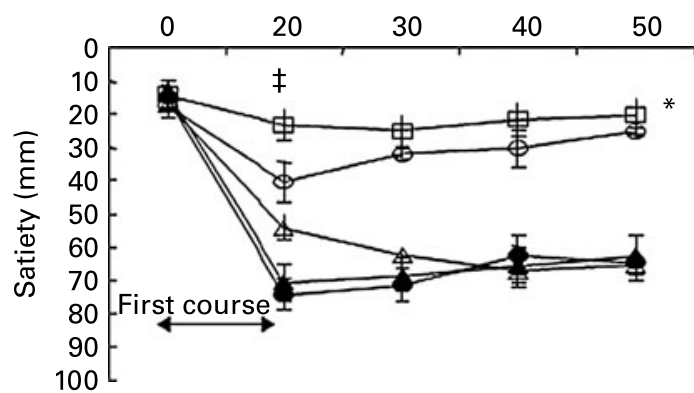

(b)

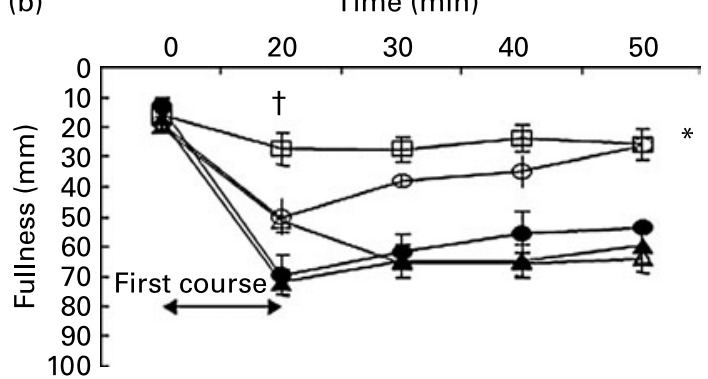

(d)

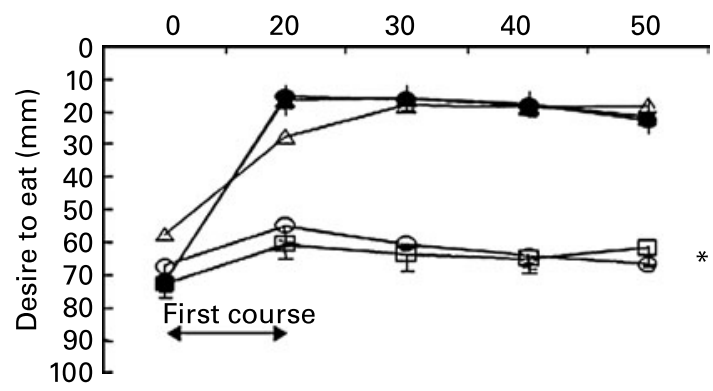

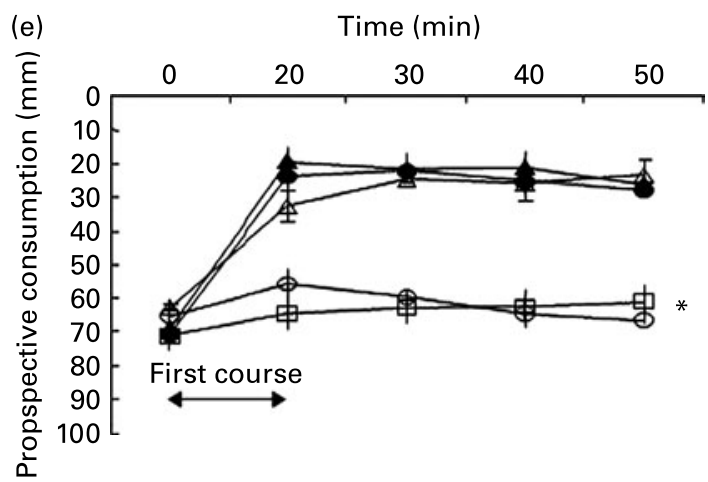

Fig. 2. Hunger (a), fullness (b), satiety (c), desire to eat (d) and prospective consumption (e) ratings before and after the start (i.e. denoted by the arrow at time $=0 \mathrm{~min}$ ) of the five first-course meal conditions that were consumed in random order over $20 \mathrm{~min}$ : (1) control (water; O); (2) fed high-protein (HP) meal with

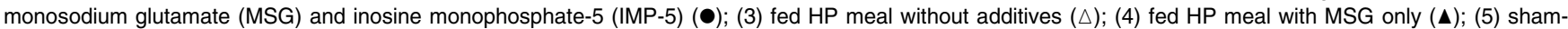
fed HP meal with MSG + IMP-5 ( $\square$ ). Values are means for ten men and twelve women $\left(n\right.$ 22), with standard errors represented by vertical bars. ${ }^{*}$ For hunger $(P<0.001)$, fullness $(P<0.001)$, satiety $(P<0.001)$, desire to eat $(P<0.001)$ and prospective consumption to eat $(P<0.001)$ there was an overall effect of meal condition as assessed by repeated-measures ANOVA. Post hoc analyses (least significance difference adjustment for multiple comparisons) found for each appetite profile that the control and sham conditions were not significantly different from each other $(P>0 \cdot 1)$, the three fed conditions were not significantly different from each other $(P>0.1)$ but the control and sham conditions were significantly different from the three fed conditions $(P<0.001)$. $†$ Fullness recorded at immediately after the first course for the sham condition was significantly different from all the conditions (all $P<0.05$ ). $\ddagger$ Satiety recorded at immediately after the first course for the sham condition was significantly different from all conditions (all $P<0.001)$, except the control $(P=0 \cdot 21)$. 


\section{Changes in glucose, insulin and glucagon-like peptide 1}

Glucose, insulin and GLP-1 are shown in Fig. 3. An overall effect of condition was observed on glucose, insulin and GLP-1 (all $P<0 \cdot 001$ ). Glucose and insulin concentrations were raised more following the three HP fed conditions than either the sham or the control conditions (post hoc comparisons all $P<0.05)$ but there was no difference in response between the three HP fed conditions with or without MSG and IMP-5. GLP-1 concentrations were raised more greatly after the HP meal with added MSG + IMP-5 than the control ( post hoc $P=0 \cdot 013$ ), and all three HP fed conditions raised the concentrations more than the sham-fed condition (post hoc comparisons all $P<0.05)$ but there was no difference in the GLP-1 responses between any of the HP conditions with or without MSG (post hoc all $P>0 \cdot 12$ ). Glucose, insulin and GLP-1 concentrations did not differ between the sham and control conditions.

\section{Energy and macronutrient intakes at the buffet}

Energy and macronutrient intakes at the second-course buffet are shown in Table 2. An overall effect of condition was observed on absolute energy intake and on intakes of protein, carbohydrate and fat $(P<0 \cdot 001)$. Energy intake was not

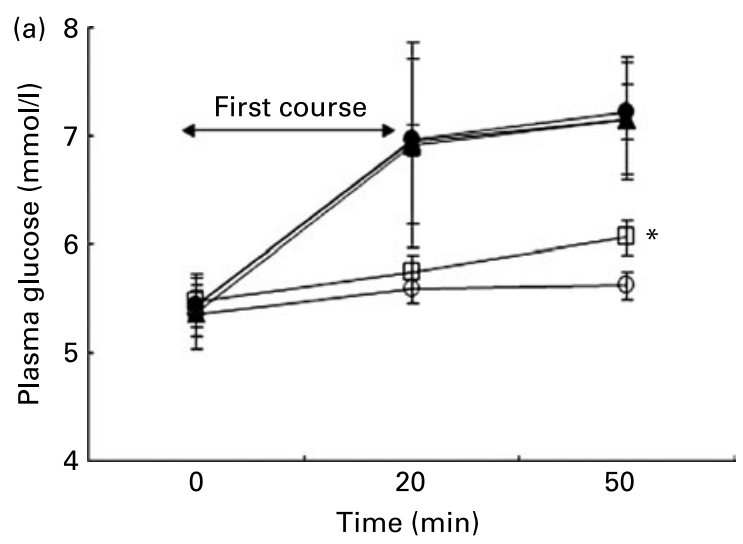

different following the $\mathrm{HP}+\mathrm{MSG}+\mathrm{IMP}$ as compared with the HP + MSG only condition $(P=0.08)$, or for the HP + MSG + IMP compared with HP no additives condition $(P=0.21)$. However, 0.64 (SEM 0.20) MJ more energy was consumed following the HP + MSG-only compared with the HP no-additives condition $(P=0 \cdot 005)$. Energy intake after each of the three HP fed conditions when compared with both the control and sham-fed conditions were lower (all post hoc comparisons $P<0 \cdot 001)$. However, the percentage energy consumed at the second course (relative to what was consumed after the control) was greatest for the HP with MSG-only condition (59 (SEM 8) \%), followed by the HP with MSG + IMP-5 condition (46 (SEM 9) \%), and then the HP no-MSG condition (39 (SEM 11) \%) (post hoc all $P<0 \cdot 01)$. This amount was significantly greater after the $\mathrm{HP}+\mathrm{MSG}$ condition than after the HP no-additives condition (post hoc $P=0.01$ ) but was not significantly different from what was consumed in the $\mathrm{HP}+\mathrm{MSG}+\mathrm{IMP}-5$ condition (post hoc comparison, $P=0 \cdot 09$ ). There was no difference between the HP + MSG + IMP and HP no-additive conditions (post hoc comparison, $P=0.34$ ). In the sham-fed condition they under-ate as compared with the control by 1 (SEM 6) \% (because recovery of food in the sham condition was not complete, i.e. 88 (SEM 2.2) \%, we assumed that the energy of this condition was $10 \%$ of meal condition 2 for
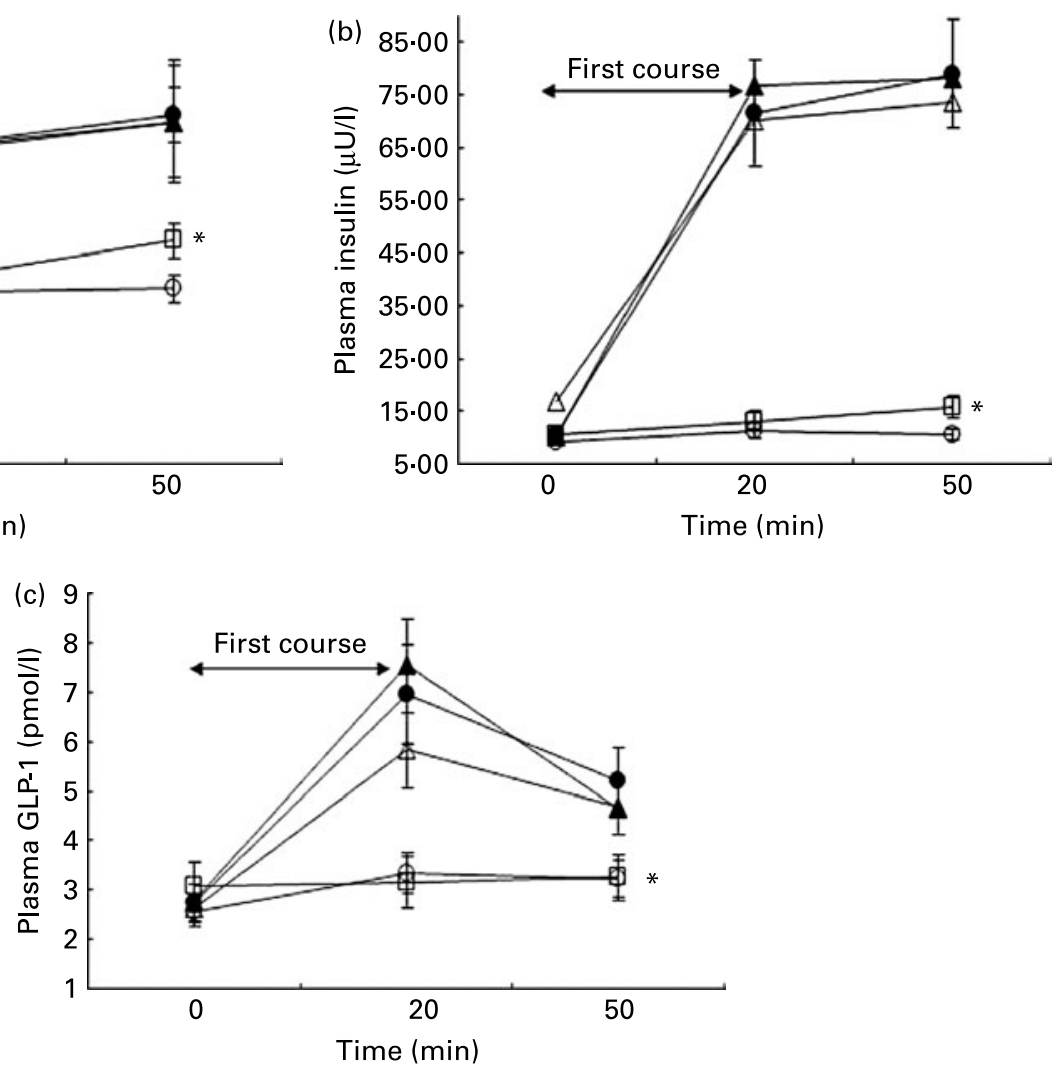

Fig. 3. Plasma glucose (a), insulin (b) and glucagon-like peptide 1 (GLP-1) (c) profiles before and after the start of the five first-course meal conditions that were consumed in random order at time $=0$ min (denoted by the arrow): (1) control (water; O); (2) fed high-protein (HP) meal with monosodium glutamate (MSG)

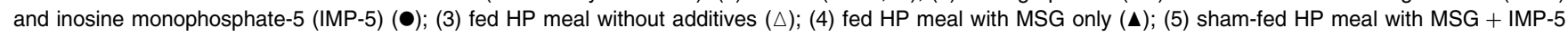
$(\square)$. Values are means for ten men and twelve women $(n 22)$, with standard errors represented by vertical bars. ${ }^{\star}$ For the plasma profiles of glucose $(P<0.001)$, insulin $(P<0.001)$ and GLP-1 $(P<0.001)$ there was an overall effect of meal condition. Post hoc analyses (least significant difference adjustment for multiple comparisons) done for each analyte found that the control and sham conditions were not significantly different from each other $(P>0 \cdot 1)$, the three fed conditions were not significantly different from each other $(P>0 \cdot 1)$ but the control and sham conditions were significantly different from the three fed conditions $(P<0.001)$. 
all subjects). An overall condition effect was observed for the absolute weight of protein, carbohydrate and fat intakes eaten at the buffet. However, when expressed as a percentage of total energy consumed, only fat intake was significantly affected by meal condition; it was less following the conditions of HP with added MSG + IMP-5 and HP with no additives as compared with both the control and sham-fed conditions respectively $(P<0 \cdot 001)$ (Table 2$)$.

\section{Relationship between the taste detection threshold for monosodium glutamate $+0.25 \%$ inosine monophosphate -5 and energy intake}

A significant relationship between the lowest concentration of MSG $+0.25 \%$ IMP-5 tasted by subjects and energy intake at the second course $(r-0.24 ; P=0.013)$ was found.

\section{Discussion}

The main findings of the present study are that the addition of MSG (alone or in combination with IMP-5) to a HP meal does not influence the perceptions of appetite or satiety, or accelerate changes in the release of GLP-1, glucose or insulin, any more than a HP meal without MSG. However, our data do suggest that the addition of MSG may increase energy intake at a second course. The study also showed that: (i) sham feeding a HP meal with added MSG does not elicit cephalic responses that affect postprandial satiety and subsequent food intake any more greatly than drinking an equal volume of water; (ii) the addition of $0.6 \% \mathrm{MSG}+0.25 \%$ IMP-5 to a HP meal appears to only subtly increase its pleasantness and this effect is very subjective; (iii) the taste detection threshold of individuals for the taste of MSG $+0.25 \%$ IMP-5 is negatively associated with energy intake at a subsequent ad libitum meal.

In the present study, all five test meals were rated as being similar in their 'pleasantness' upon the first taste. This contrasts with findings reported by others ${ }^{(19-22)}$ who showed significant increases in pleasantness with the addition of MSG. However, even though our pleasantness ratings were similar, there was a trend for them to be greater in the conditions with added MSG and the greatest pleasantness, although not statistically significant, was achieved with the addition of MSG + IMP-5. The lack of a statistical significance undoubtedly reflects a lack of study power (i.e. actual power is $58 \%$, $\alpha=0.05$ ) and individual variance in rating the hedonic values of foods.

Appetite perceptions were not affected by the addition of MSG alone, or in combination with IMP-5, in the present study. This is in agreement with Rogers \& Blundell ${ }^{(22)}$ who reported that a $10 \mathrm{~kJ}$ soup preload enriched with MSG reduced hunger and desire to eat, and increased fullness to a similar extent as a $10 \mathrm{~kJ}$ soup without added MSG. No other studies to our knowledge have assessed the effect of MSG on perceptions of appetite.

In the present study, we also hypothesised that any effect of MSG (alone or in combination with IMP-5) on appetite perceptions and subsequent energy intake would be related to changes in the release of GLP-1 from the gastrointestinal tract, or in insulin and glucose. The increase in insulin, glucose and GLP-1 concentrations that we observed following 
the three fed HP conditions relative to the control and sham conditions most probably reflects increased carbohydrate and protein content, and increased energy. Although, there was no significance difference between the three fed HP conditions in these responses, it does appear that MSG alone and in combination with IMP-5 can increase insulin and GLP-1 concentrations marginally more than if no MSG is added to a HP meal. Further investigation may be warranted to clarify this observation. That the concentrations of insulin, glucose and GLP-1 barely increased after the control and sham conditions reflects the regulation of these analytes by nutrients. No other studies to our knowledge have examined the effect of MSG on GLP-1 or other satiety hormones. Chevassus et al. ${ }^{(34)} \mathrm{did}$, however, examine MSG's effect on insulin secretion. They reported that $10 \mathrm{~g}$ encapsulated MSG, when administered simultaneously with an oral glucose load, increased glucoseinduced insulin secretion in a concentration-dependent manner in eighteen healthy volunteers. Plasma glucose was not lowered in their study, but a study in rats showed that as insulin concentrations were increased by added MSG to the diet, glucose tolerance improved ${ }^{(35)}$.

Given that (i) protein is the most satiating macronutrient, (ii) Rogers \& Blundell ${ }^{(22)}$ observed a reduction in hunger and desire to eat following the consumption of MSG-enriched soup (albeit to an equal extent as a soup without MSG) and (iii) protein intake can be increased when MSG is added (albeit not significantly in statistical terms) ${ }^{(23)}$, we formulated our hypothesis that the consumption of a HP meal enriched with MSG alone or MSG + IMP would lead to an earlier satiety and thereby reduce energy intake at a subsequent second course. Energy intake, however, was increased (on average) by $0.644 \mathrm{MJ}$ following the HP condition with added MSG as compared with no added MSG. Given that we also observed a significant negative association between energy intake at the buffet meal and the taste detection threshold of individuals for the taste of $\mathrm{MSG}+0.25 \%$ IMP-5, our findings may raise some concern for users of MSG, particularly those who are sensitive to its taste. On the other hand, the observed association was weak. Moreover, it is interesting that energy intake following the HP + MSG + IMP condition was not significantly different from the HP noadditives condition. The present study was sufficiently powered ( $80 \%$ power, $\alpha=0.05)$ to detect differences between the three HP fed conditions to the magnitude of 0.65 (SEM 0.96) MJ. If the 256 (SEM 938) MJ difference between the HP + MSG + IMP condition and the HP no-additives condition were statistically significant, it would have detected it despite the large within-subject variation in responses. Therefore, further research, in human subjects, is necessary to confirm the effects of MSG on energy intake, and perhaps using MSG in combination with IMP-5 can prevent MSG-induced over-consumption if it is a real phenomenon in humans. Ideally, a larger population with equal number of tasters at both ends of the MSG taste sensitivity range would clarify these results.

At the second-course buffet, we anticipated that subjects might reduce their overall energy intake by continuing to eat foods that exuded the similar 'meaty' and/or 'savoury' taste as provided in the first course (i.e. buffet included ham, hard cheese and unsalted peanuts) until they reached 'sensoryspecific satiety'. The buffet foods that provided those sensory properties were all higher in protein than the other foods that had a higher carbohydrate content and which provided more of a 'sweet' and/or 'creamy/fatty' taste (i.e. sweet cookies, rice cream, cream-topped custard, potato crisps). We did also include, however, some higher-protein items with a 'sweet' and/or 'creamy/fatty' taste (i.e. natural yoghurt, fruit yoghurt and a protein snack bar). Of course, what might have happened was that the subjects had reached 'sensory-specific satiety' at the end of the first course because it was a relatively large energy load (i.e. $2 \cdot 2 \mathrm{MJ}$ on average). Therefore, at the next course, they may have eaten to satisfy their desire for another taste sensation. In addition, the $30 \mathrm{~min}$ break between the first and second courses may have been too long and thereby any desire to continue eating foods with similar sensory properties was lost. Furthermore, our buffet design may have limited our ability to see any effect because we closely matched the overall fat content of the six foods that provided the 'meaty'/'savoury' taste to those that provided the 'sweet' or 'creamy/fatty' taste. It is also possible that some individuals ate a bit of everything, and because the food items were similar in their fat content, the increase in the percentage energy derived from fat that we observed was the cause of the increased energy intake between the HP conditions with and without MSG. The addition of MSG to the diet of rats (but not when ingested in the absence of energy) has also been shown to increase the thermic effect of feeding and promote a rapid switch in substrate utilisation ${ }^{(36)}$ over the first $30 \mathrm{~min}$ after the test meal. Although we did not measure these indices, we believe that they would have been underlying mechanisms of an early satiety and reduced energy intake, had we found that to occur in the present study.

The sham-fed HP condition with added MSG and IMP-5 was included in the study design to discriminate the pre-ingestive/cephalic effects of the HP meal with MSG (alone or in combination with IMP-5) (i.e. those evoked by the thought, sight, smell and taste only) from the post-ingestive effects. The results revealed that thinking, seeing, smelling and tasting the meal containing MSG + IMP-5 had no significantly greater impact on post-ingestive and post-absorptive appetite and metabolism than did drinking an equal volume of water (i.e. mechanical effect).

We conclude that the addition of MSG to a HP meal does not influence perceptions of satiety but it may increase energy intake at a second course. Cephalic responses observed after the sham-fed HP + MSG + IMP-5 condition were of similar magnitude as the control. This provides evidence that just tasting food is not enough to influence satiety and energy intake. GLP-1 was not involved in cephalic or postprandial responses observed in the present study. Further research, in human subjects, is warranted to clarify the effect of MSG on energy intake and feeding behaviour. A study in a larger population with equal numbers of 'highly sensitive' and 'not sensitive at all' tasters of MSG may provide some insight into mechanisms that lead some individuals (but not all) to over-consume energy when food is enriched with MSG.

\section{Acknowledgements}

We would like to thank Loek Wouters for analysing the ${ }^{2} \mathrm{H}$-labelled urine samples for determination of body composition, and Jos Stegen and Wendy Sluijsman for analysing 
the blood samples for glucose and insulin. N. D. L.-M. designed the experiment, collected the data, analysed the data and wrote the manuscript. A. J. P. G. S. read the manuscript and contributed to the discussion. M. S. W.-P. helped to design the experiment, analyse the data and write the manuscript, and supervised the project. The present study was supported by project funding (RTD line 5, Obesity and Food Technology) from The European DiOGenes program 20022006 and Top Institute Food \& Nutrition, The Netherlands.

None of the authors had any financial or personal interest in any company or organisation sponsoring the research.

\section{References}

1. Lejeune MP, Westerterp KR, Adam TC, et al. (2006) Ghrelin and glucagon-like peptide 1 concentrations, 24-h satiety, and energy and substrate metabolism during a high-protein diet and measured in a respiration chamber. Am J Clin Nutr 83, 89-94.

2. Luscombe ND, Clifton PM, Noakes M, et al. (2003) Effect of a high-protein, energy-restricted diet on weight loss and energy expenditure after weight stabilization in hyperinsulinemic subjects. Int J Obes Relat Metab Disord 27, 582-590.

3. Porrini M, Crovetti R, Testolin G, et al. (1995) Evaluation of satiety sensations and food intake after different preloads. Appetite 25, 17-30.

4. Stubbs RJ, van Wyk MC, Johnstone AM, et al. (1996) Breakfasts high in protein, fat or carbohydrate: effect on within-day appetite and energy balance. Eur J Clin Nutr 50, 409-417.

5. Weigle DS, Breen PA, Matthys CC, et al. (2005) A high-protein diet induces sustained reductions in appetite, ad libitum caloric intake, and body weight despite compensatory changes in diurnal plasma leptin and ghrelin concentrations. Am J Clin Nutr 82, $41-48$.

6. Westerterp-Plantenga MS, Rolland V, Wilson SA, et al. (1999) Satiety related to $24 \mathrm{~h}$ diet-induced thermogenesis during high protein/carbohydrate vs high fat diets measured in a respiration chamber. Eur J Clin Nutr 53, 495-502.

7. Latner JD \& Schwartz M (1999) The effects of a high-carbohydrate, high-protein or balanced lunch upon later food intake and hunger ratings. Appetite 33, 119-128.

8. Kurihara K \& Kashiwayanagi M (2000) Physiological studies on umami taste. J Nutr 130, Suppl. 4S, 931S-934S.

9. Yamaguchi S \& Ninomiya K (2000) Umami and food palatability. J Nutr 130, Suppl. 4S, 921S-926S.

10. Luscombe-Marsh ND, Smeets AJ \& Westerterp-Plantenga MS (2008) Taste sensitivity for monosodium glutamate and an increased liking of dietary protein. Br J Nutr 99, 904-908.

11. Smriga M \& Torii K (2000) Release of hypothalamic norepinephrine during MSG intake in rats fed normal and nonprotein diet. Physiol Behav 70, 413-415.

12. He W, Yasumatsu K, Varadarajan V, et al. (2004) Umami taste responses are mediated by $\alpha$-transducin and $\alpha$-gustducin. J Neurosci 24, 7674-7680.

13. Ruiz CJ, Wray K, Delay E, et al. (2003) Behavioural evidence for a role of $\alpha$-gustducin in glutamate taste. Chem Senses 28, 573-579.

14. Naim M, Ohara I, Kare MR, et al. (1991) Interaction of MSG taste with nutrition: perspectives in consummatory behavior and digestion. Physiol Behav 49, 1019-1024.

15. Mori M, Kawada T, Ono T, et al. (1991) Taste preference and protein nutrition and L-amino acid homeostasis in male Sprague-Dawley rats. Physiol Behav 49, 987-995.

16. Kondoh T, Mori M \& Ono T (2000) Mechanisms of umami taste preference and aversion in rats. J Nutr 130, Suppl. 4S, 966S-970S.
17. Laska M \& Hernandez Salazar LT (2004) Gustatory responsiveness to monosodium glutamate and sodium chloride in four species of nonhuman primates. J Exp Zoolog A Comp Exp Biol 301, 898-905.

18. Murphy C (1987) Flavour preference for monosodium glutamate and casein hydrolysate in young and elderly persons. In Umami: A Basic Taste, pp. 139-151 [Y Kawamura and MR Kare, editors]. New York: Marcel Dekker.

19. Bellisle F, Tournier A \& Louis-Sylvestre J (1989) Monosodium glutamate and the acquistion of food preferences in a Europrean context. Food Qual Pref 1, 103-108.

20. Bellisle F, Monneuse MO, Chabert M, et al. (1991) Monosodium glutamate as a palatability enhancer in the European diet. Physiol Behav 49, 869-873.

21. Bellisle F, Dalix AM, Chapppuis AS, et al. (1996) Monosodium glutamate affects mealtime food selection in diabetic patients. Appetite 26, 267-275.

22. Rogers PJ \& Blundell JE (1990) Umami and appetite: effects of monosodium glutamate on hunger and food intake in human subjects. Physiol Behav 48, 801-804.

23. Essed NH, van Staveren WA, Kok FJ, et al. (2007) No effect of 16 weeks flavor enhancement on dietary intake and nutritional status of nursing home elderly. Appetite 48, 29-36.

24. Heath RB, Jones R, Frayn KN, et al. (2004) Vagal stimulation exaggerates the inhibitory ghrelin response to oral fat in humans. J Endocrinol 180, 273-281.

25. Robertson MD, Mason AO \& Frayn KN (2002) Timing of vagal stimulation affects postprandial lipid metabolism in humans. Am J Clin Nutr 76, 71-77.

26. Robertson MD, Jackson KG, Williams CM, et al. (2001) Prolonged effects of modified sham feeding on energy substrate mobilization. Am J Clin Nutr 73, 111-117.

27. Stunkard AJ \& Messick S (1985) The three-factor eating questionnaire to measure dietary restraint, disinhibition and hunger. J Psychosom Res 29, 71-83.

28. Westerterp KR, Wouters L \& van Marken-Lichtenbelt WD (1995) The Maastricht protocol for the measurements of body composition and energy expenditure with labeled water. Obes Res 3, 49-57.

29. Westerterp KR (1999) Body composition, water turnover and energy turnover assessment with labelled water. Proc Nutr Soc 58, 945-951.

30. Harris JA \& Benedict FG (1918) A biometric study of human basal metabolism. Proc Natl Acad Sci U S A 4, 370-373.

31. Bellisle F (1999) Glutamate and the Umami taste: sensory, metabolic, nutritional and behavioural considerations. A review of the literature published in the last 10 years. Neurosci Biobehav Rev 23, 423-438.

32. Homsey C (2001) Food product design elements; flavour enhancement: taking taste from so-so to spectacular. http:// www.foodproductdesign.com/archive/2001/1001de.html

33. Chapman IM, Goble EA, Wittert GA, et al. (1999) Effects of small-intestinal fat and carbohydrate infusions on appetite and food intake in obese and nonobese men. Am J Clin Nutr 69, 6-12.

34. Chevassus H, Renard E, Bertrand G, et al. (2002) Effects of oral monosodium (L)-glutamate on insulin secretion and glucose tolerance in healthy volunteers. Br J Clin Pharmacol 53, 641-643.

35. Viarouge C, Even P, Rougeot C, et al. (1991) Effects of metabolic and hormonal parameters of monosodium glutamate (Umami taste) ingestion in the rat. Physiol Behav 49, 1013-1018.

36. Viarouge C, Caulliez R \& Nicolaidis S (1992) Umami taste of monosodium glutamate enhances the thermic effect of food and affects the respiratory quotient in the rat. Physiol Behav 52, 879-884. 